\title{
Sustainable Cotton Production through Skill Development among Farmers: Evidence from Khairpur District of Sindh, Pakistan
}

\author{
MuHAMMAD AZEem KHAN and MUHAMMAD IQBAL
}

\section{INTRODUCTION}

Pakistan is the world's fourth largest producer and one of the major cottonexporting countries. Cotton is grown largely in Punjab and Sindh provinces and accounts for about 10.5 percent of the value-added in the agriculture sector. The majority of cotton growers are smallholders and a large number of them are tenant farm households. Frequent pest outbreaks since the early 1990s have induced pesticide-based farming in Pakistan. Also, the liberalisation of generic pesticide import has resulted in a many-fold increase in pesticide use in the country. However, this has neither increased cotton productivity nor the prosperity of the poor cotton growers [Poswal and Williamson (1998) and Ahmad and Poswal (2000)].

In Pakistan, research and development in Integrated Pest Management (IPM) was initiated in the 1970s. However, the efforts to implement IPM at the farm level were not very successful. Pesticides became a major instrument of production leading to a 'pesticide treadmill' situation [Irshad (2000)]. An analysis of pesticide policies through the UNDP-FAO Policy Reform Project paved the way for the establishment of a National IPM Programme and provided instruments to scale up farmer-led IPM through joint international and national efforts on various fronts. Pesticide policy studies estimated environmental and social cost of pesticides in Pakistan at US\$ 206 million per year [UNDP (2001) and Azeem, et al. (2003)]. About 49 percent of these external costs were attributed to pest resistance problems, while 29 percent to loss in bio-diversity and nearly 20 percent occurred to human and animal health. On the other hand, damage prevention expenditures for residue monitoring and raising public awareness on the dangers of pesticides is less than 2 percent of the total social costs of pesticides.

Muhammad Azeem Khan is Principal Scientific Officer, Policy Analysis and R\&D Component, National IPM Programme, NARC, Islamabad. Muhammad Iqbal is Senior Research Economist, Pakistan Institute of Development Economics, Islamabad. 
Other studies have also shown that over- and misuse of pesticides has led to tremendous economic losses and hazards to human health [Azeem (2000); Feenstra et al. (2000); Orphal (2001) and Ahad, et al. (2001)]. The results of the pesticide policy analysis and the onset of the FAO-EU IPM Programme for Cotton in Asia led to the establishment of a National IPM Programme of Pakistan in December 2000. During 2001, the Training of Facilitators (TOF) and Farmers Field School (FFS) activities were initiated in the cotton growing areas of Sakrand and Khairpur Districts of Sindh Province of Pakistan, which were later expanded to other areas and provinces, i.e. Punjab and Balochistan.

The FFS approach aims at generating a deeper understanding of the important interactions of agro-ecosystems as well as on sustainable farming, with the particular emphasis on reduction of chemical pesticide use [Berg, et al. (2004)]. The crop management practices of FFS farmers are expected to change as a result of training process. Discovery based learning methodologies used for the training are expected to foster experimental and analytical capacities of the FFS farmers for making rational decisions under complex and changing circumstances. Each FFS participant learns improved crop management skills through group activities by attending around 22 training sessions expanded over whole crop production season. The curriculum followed in the season long training includes transfer of skills regarding critical crop management practices like seed selection, seed treatment, land preparation, soil fertility management, irrigation, agro-ecosystem analysis, plant protection measures, and harvest and post harvest handling. The ultimate purpose of this rigorous training is to achieve a significant improvement in the crop and pest management knowledge and promote best agricultural practices of the farmers for sustainable crop production.

Although the cost saving attribute of FFS based IPM approach is widely accepted but still long run effects of this approach are being questioned at policy level that it may adversely affect the realisation of national production targets and/or may harm farm level technical efficiency. The present analysis also focuses on estimating the impact of FFS approach on farm level efficiency to provide empirical basis for decision-making at policy level. The specific objectives of the study include:

(i) to measuring changes in farmers beliefs, attitude, and decision-making capacities for a sustainable use of IPM practices;

(ii) to assessing changes in the production practices of cotton-growers;

(iii) to quantifying the effect of FFS training on farm income; and

(iv) to analysing the impact of FFS trainings on farm level efficiency by estimating a stochastic production frontier incorporating inefficiency components.

The paper is organised into four parts. The Section II discusses methodology and empirical model. The results are presented in Section III and the final section concludes findings and suggests policy recommendations. 


\section{METHODOLOGY}

\section{Study Area and Sample Size}

The impacts on various indicators of improved cotton production through FFS processes were assessed in Khairpur District of Sindh province of Pakistan. The district was selected because of the presence of a large number of small and tenant farm households and increasing pesticide use scenarios in the area. The low household incomes and high poverty profile in the area were the other factors behind this selection.

At the second stage, 4 FFS villages were randomly selected from four different clusters of FFS situated in 4 adjoining Tehsils. In addition, 4 control villages were selected from the adjoining Sukkur District (about 60 kilometres away from the nearest FFS project areas). The list frame on structural and operational variables including farmers' age, education, farm size, cotton area, and irrigation sources was developed to determine similarities in the overall profile of project and control area farms as cautioned by Casely and Kumar (1987). Selection of control villages was finalised after analysing the list frame data and finding certain level of similarities in farm characteristics and cotton production practices of IMP and Control villages' farms.

The total sample for the baseline survey was consisted of 100 FFSparticipating farmers and 120 non-FFS or control farmers (from FFS and control villages). However, out of 220 farmers included in the baseline only 190 farmers could be interviewed for this study (78 FFS, 59 Non-FFS, and 53 control farmers) because a number of the FFS farmers, who initially joined but abandoned FFS after few sessions, were not considered for the post-FFS survey. Moreover, certain tenant farmers of FFS, Non-FFS, and control groups left their previous landlords and shifted to other villages or moved to farms of other landlords in the same village had to be dropped from the post-FFS survey.

\section{Data Collection and Transformations}

The baseline survey was conducted during July 2002 immediately after the formation of the FFS training groups and information was collected regarding cotton crop 2001. The post FFS-impact survey was conducted during cotton season of 2003 through multiple visits in three rounds. A set of both qualitative and quantitative impact assessment indicators was determined for data collection [Guijt (1998) and Abbot and Guijt (1998)].

The biodiversity scores of the sample farmers were developed from their responses to questions on probable crop losses they would suffer in the absence of pesticides use. The scoring of their attitudes towards the environment was based on the extent of respondents' agreement on six statements narrated to them in local 
language. These statements carried weights and included growers' belief in cultural and biological methods of crop protection, consideration of pesticide use as sole crop protection solution, perceptions on biodiversity losses, understanding on pesticide threat to environment, know-how on pesticide hazards to all living organisms, and beliefs on health risks of spraying.

The relative scoring of responses was assigned to questions and statements related to the important decision-making attributes. These weighted scoring was decided in consultation with FFS-facilitators and those questions or statements that contribute more in making rational crop production decisions were weighted high. The scoring on field experimentation skills was assessed through assigning weights (see number in parentheses) to experimentation initiatives undertaken by the farmers including early planting (10), late planting (10), trap crops (20), change in variety (20), controlling pests physically (10) and experimentation on pesticide chemical alternatives such as water spray, plant extracts sprays, detergent spray etc. (30). The decision-making empowerment scoring was performed on using different decision aids like self-conducted ecosystem analysis including pest scouting (40), consulting fellow farmers (20), relying on own knowledge (10), reading labels (20) and watching/listening agriculture programme on TV/radio (10).

The social recognition of sample farmers was assessed through assigning different scores if other farmers contacted him for discussion on social and technical matters, which were categorised as contacted by less than 5 farmers (10), contacted by 5 to 10 farmers (20) and contacted by more than 10 farmers (40), office bearer (20) and just member (10) of a farmer group.

\section{Analytical Methods}

The analytical methods include single difference comparisons of change in production practices between FFS trained and non-trained farmers, the difference in difference (DD) method [Feder, et al. (2003)] for comparisons among FFS trained farmers, FFS exposed farmers and un-exposed farmers from control villages. As a first explorative step, group means of relevant economic parameters were compared by using t-test for the before-after comparison and using $F$-test for the betweengroup comparison [Praneetvatakul and Waibel (2001)]. The DD method was used to compare means, standard deviations and paired $t$-test statistics to test for differences in gross margins, production practices and input use levels among FFS, non-FFS, and control farms. The variable inputs were valued based on market prices. The opportunity costs were estimated for the operations performed by own farm machines, family labour and farm inputs (farm yard manure and seed). Monetary costs account for inputs such as fertiliser, herbicide, insecticide, fuel, improved seed, casual hired labour, cotton picking, and transporting output. The gross margin for cotton activity is estimated as the difference between per-unit revenue and total variable input costs. 
The stochastic production frontier model incorporating inefficiency effects, specified by Battese and Coelli (1995), is used to analyse the impact of farmers' training (through FFS) on productivity and efficiency at cotton farms in the study area. The stochastic production frontier and the technical efficiency component of the model are specified in Equations 1 and 2 respectively.

\section{Stochastic Production Frontier}

$$
\begin{aligned}
\operatorname{Ln}\left(Y I E L D_{i t}\right)= & \beta_{0}+\beta_{1} \operatorname{Ln}\left(\operatorname{LABOR}_{i t}\right)+\beta_{2} \operatorname{Ln}\left(\operatorname{SEED}_{i t}\right)+\beta_{3} \operatorname{DCHEM}_{i t}+\beta_{4} \operatorname{Ln}\left(C H E M_{i t}\right) \\
& +\beta_{5} \operatorname{Ln}\left(N F E R T_{i t}\right)+\beta_{6} \operatorname{DPFERT}_{i t}+\beta_{7} \operatorname{Ln}\left(P F E R T_{i t}\right)+V_{i t}-U_{i t} \quad \ldots
\end{aligned}
$$

Where

$$
\begin{aligned}
i= & \text { indicates the } i \text { th farm; } \\
L n= & \text { natural logarithm (i.e. logarithm to base } e \text { ); } \\
Y I E L D_{i t}= & \text { cotton yield at the } i \text { th farm (kgs/hectare) in tth time period; } \\
L A B O U R_{i t}= & \text { labour input at the } i \text { th farm (number/per hectare) in th time } \\
& \text { period; } \\
S E E D_{i t}= & \text { seed rate at the ith farms (kgs/hectare) in tth time period; } \\
D C H E M_{i t}= & 1, \text { if chemicals are not used on } i \text { th farms and } 0 \text { otherwise; } \\
C H E M_{i t}= & \text { volume of chemical used at ith farms (ml/hectare) in tth time } \\
& \text { period; } \\
N F E R T_{i t}= & \text { nitrogen fertiliser nutrients applied on ith farms (kgs/hectare) in } \\
& \text { th time period; } \\
D P F E R T_{i t}= & 1, \text { if farmer does not use P-nutrient on the ith farm and } 0 \\
& \text { otherwise; } \\
P F E R T_{i t}= & \text { phosphorus fertiliser nutrient used at ith farm (kgs/hectare) in tth } \\
& \text { time period; } \\
\beta s= & \text { unknown parameters to be estimated; } \\
V_{i t}= & \text { random error terms which are assumed to be independently and } \\
& \text { identically distributed assuming normal distribution with mean } 0 \\
& \text { and variance } \sigma_{V}^{2} \text { and independent of the } U_{i t} ; \\
U_{i t}= & \text { non-negative random variable indicating technical inefficiency } \\
& \text { of farmers that assumes half normal distribution truncated at } \\
& \text { zero and has variance } \sigma_{U}^{2} \text {. }
\end{aligned}
$$

\section{Technical Inefficiency Component}

$$
\begin{aligned}
& U_{i}=\delta_{0}+\delta_{1}\left(\text { DYEAR }_{i}\right)+\delta_{2}\left(\text { DMFFS }_{i}\right)+\delta_{3}\left(\text { AGE }_{i}\right)+\delta_{4}\left(\text { DPRIMARY }_{i}\right) \\
& +\delta_{5}\left(\text { DMATRIC }_{i}\right)+\delta_{6}\left(\text { DHIGHER }_{i}\right)+W_{i} \quad \ldots \quad \ldots \quad \ldots
\end{aligned}
$$

Where

$$
\begin{aligned}
D Y E A R_{i} & =1 \text {, if observations belong to normal year } 2001 \text { and } 0 \\
& \text { otherwise; }
\end{aligned}
$$


$D M F F S_{i}=1$, if farmer is member of FFS; 0 otherwise;

$A G E_{i}=$ Age of $i$ th farmer (in years);

$\operatorname{DPRIMARY}_{i}=1$, if $i$ th farmer has 5 years or less of formal schooling; 0 otherwise;

$\operatorname{DMATRIC}_{i}=1$, if $i$ th farmer has more than 5 but less than or equal to 10 years of formal schooling; 0 otherwise;

$D_{H I G H E R_{i}}=1$, if $i$ th farmers has more than 10 years of formal education; 0 otherwise;

$W_{i}=$ is an unobservable random variable assuming truncated normal distribution with mean zero and variance $\sigma_{w}^{2}$.

Based on the specification of the stochastic frontier and inefficiency models given in Equations 1 and 2, technical efficiency measures for the ith farm can be estimated as

$$
T E_{i}=E X P\left(-U_{i}\right)=\frac{Y I E L D_{i}}{Y I E L D_{i}^{*}}
$$

Where $Y I E L D_{i}$ is observed cotton yield and $Y I E L D_{i}{ }^{*}$ is the maximum possible yield using the given level of inputs.

\section{RESULTS AND DISCUSSION}

\section{Differences in Knowledge and Skills}

The before-after comparison among the three farmer groups indicates that in general FFS training has enhanced the human capacity of the participants (Table 1). The $F$-values showed significant differences for all variables among various groups after the training. While for three variables such differences existed already before the training, however, the level of significance of the differences was higher after the training. The mean scores of FFS farmers increased for all variables and in some cases it doubled. In case of control farmers, the change was relatively smaller and in some cases even negative. The same pattern of before-after difference observed for the control group could be observed for the exposed farmers (Non-FFS) indicating that enhancement of human capacity mainly depended on training participation and is less likely to spread by other communication channels.

The paired comparisons were performed for the three groups of farmers in before-after training situation in order to illustrate the differences in the human capacity performance parameters and the results are shown in Table 2. These comparisons demonstrate the positive change for FFS farmers while the differences were comparatively smaller and highly variable between the other two groups. 
Table 1

Change in the Human Capacities for Practice Changes

\begin{tabular}{|c|c|c|c|c|c|c|c|c|c|c|c|c|}
\hline \multirow[b]{2}{*}{ Year } & \multirow[b]{2}{*}{ Types } & \multirow[b]{2}{*}{$\mathrm{N}$} & \multicolumn{2}{|c|}{$\begin{array}{l}\text { Decision- } \\
\text { making Skill } \\
\text { Score (\%) }\end{array}$} & \multicolumn{2}{|c|}{$\begin{array}{c}\text { Field } \\
\text { Experiments } \\
\text { Score (\%) }\end{array}$} & \multicolumn{2}{|c|}{$\begin{array}{l}\text { Observed } \\
\text { Biodiversity } \\
\text { Score (\%) }\end{array}$} & \multicolumn{2}{|c|}{$\begin{array}{c}\text { Attitude } \\
\text { Towards } \\
\text { Environment } \\
\text { Score (\%) }\end{array}$} & \multicolumn{2}{|c|}{$\begin{array}{c}\text { Social } \\
\text { Recognition }\end{array}$} \\
\hline & & & Mean & $\mathrm{SD}$ & Mean & SD & Mean & SD & Mean & $\overline{S D}$ & Mean & SD \\
\hline \multirow[t]{5}{*}{2001} & FFS & 78 & 16.0 & 11.1 & 11.03 & 14.6 & 52.44 & 16.69 & 37.95 & 21.82 & 14 & 13.9 \\
\hline & Non-FFS & 59 & 10.3 & 8.3 & 7.80 & 12.7 & 51.19 & 19.48 & 36.10 & 22.82 & 9 & 10.5 \\
\hline & Control & 53 & 14.9 & 10.3 & 5.28 & 11.7 & 45.66 & 12.25 & 33.77 & 18.83 & 7 & 8.1 \\
\hline & Overall & 190 & 13.9 & 10.3 & 8.42 & 13.4 & 50.16 & 16.71 & 36.21 & 21.32 & 10 & 11.8 \\
\hline & Sig. & & \multicolumn{2}{|c|}{0.004} & \multicolumn{2}{|c|}{0.050} & \multicolumn{2}{|c|}{0.063} & \multicolumn{2}{|c|}{0.548} & \multicolumn{2}{|c|}{0.002} \\
\hline \multirow[t]{5}{*}{2003} & FFS & 78 & 34.5 & 25.4 & 15.26 & 15.5 & 72.05 & 14.80 & 75.90 & 32.85 & 27 & 27.9 \\
\hline & Non-FFS & 59 & 9.5 & 12.7 & 11.19 & 14.9 & 54.75 & 17.87 & 39.15 & 33.44 & 8 & 15.8 \\
\hline & Control & 53 & 9.4 & 10.8 & 6.79 & 12.7 & 46.32 & 18.06 & 29.81 & 19.46 & 8 & 19.2 \\
\hline & Overall & 190 & 19.7 & 22.3 & 11.63 & 14.9 & 59.50 & 19.94 & 51.63 & 36.22 & 16 & 24.3 \\
\hline & Sig. & & \multicolumn{2}{|c|}{0.000} & \multicolumn{2}{|c|}{0.006} & \multicolumn{2}{|c|}{0.000} & \multicolumn{2}{|c|}{0.000} & \multicolumn{2}{|c|}{0.000} \\
\hline
\end{tabular}

Table 2

Difference of Difference Estimates of the Qualitative Attribute of Farmers' Education

Pre/Post FFS Diff. $\quad$ FFS-Control Non-FFS-Control

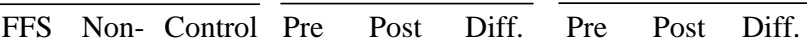

FFS

\begin{tabular}{lccccccccc}
\hline Decision-making Score & 19 & -1 & -6 & 1 & 25 & 24 & -5 & 0 & 5 \\
Experimentation Score & $(27)$ & $(13)$ & $(13)$ & & & & & & \\
Biodiversity Score & $(18)$ & $(20)$ & 2 & 6 & 8 & 3 & 3 & 4 & 2 \\
Attitude Score & 20 & 4 & 1 & 7 & 26 & 19 & 6 & 8 & 3 \\
Social Recognition Score & $(20)$ & $(26)$ & $(21)$ & & & & & & \\
& 38 & 3 & -4 & 4 & 46 & 42 & 2 & 9 & 7 \\
\hline
\end{tabular}

Note: Figures in parenthesis are Standard Deviations.

\section{Practice Differences}

The similar comparisons were also undertaken for input use and production practices. The pre FFS training difference among the three groups of farmers were insignificant in the cases of seed management and time spent on field observations (Table 3). The control farmers tended to exceed the recommended seed rate while both FFS and Non-FFS farmers maintained the seed rate within reasonable limits. The farmers often use excessive seed rates to control weeds although the effect of 
Table 3

Input Use and Field Management Practices before and after FFS Training

\begin{tabular}{|c|c|c|c|c|c|c|c|c|c|c|c|c|}
\hline \multirow[b]{2}{*}{ Year } & \multirow[b]{2}{*}{ Types } & \multirow[b]{2}{*}{$\mathrm{N}$} & \multicolumn{2}{|c|}{$\begin{array}{l}\text { Seed } \\
(\mathrm{kg} / \mathrm{ha})\end{array}$} & \multicolumn{2}{|c|}{$\begin{array}{l}\text { N Fertiliser } \\
(\mathrm{kg} / \mathrm{ha})\end{array}$} & \multicolumn{2}{|c|}{$\begin{array}{c}\text { P Fertiliser } \\
\text { (kg/ha) }\end{array}$} & \multicolumn{2}{|c|}{$\begin{array}{l}\text { No. of } \\
\text { Irrigations }\end{array}$} & \multicolumn{2}{|c|}{$\begin{array}{c}\text { Field } \\
\text { Observation } \\
\text { (Hrs/Season) }\end{array}$} \\
\hline & & & Mean & SD & Mean & SD & Mean & SD & Mean & $\overline{\mathrm{SD}}$ & $\overline{\text { Mean }}$ & $\overline{S D}$ \\
\hline \multirow[t]{5}{*}{2001} & FFS & 78 & 21 & 6 & 181 & 51 & 52 & 19 & 9 & 4 & 36 & 66 \\
\hline & Non-FFS & 59 & 21 & 6 & 171 & 47 & 54 & 24 & 9 & 5 & 32 & 53 \\
\hline & Control & 53 & 23 & 3 & 228 & 65 & 67 & 24 & 6 & 2 & 17 & 18 \\
\hline & All Farmers & 190 & 22 & 5 & 191 & 59 & 57 & 23 & 8 & 4 & 29 & 53 \\
\hline & Sig. & & \multicolumn{2}{|c|}{0.108} & \multicolumn{2}{|c|}{0.000} & \multicolumn{2}{|c|}{0.000} & \multicolumn{2}{|c|}{0.006} & \multicolumn{2}{|c|}{0.117} \\
\hline \multirow[t]{5}{*}{2003} & FFS & 78 & 23 & 8 & 197 & 66 & 45 & 30 & 8 & 3 & 66 & 60 \\
\hline & Non-FFS & 59 & 23 & 8 & 184 & 57 & 49 & 35 & 8 & 3 & 44 & 50 \\
\hline & Control & 53 & 31 & 9 & 279 & 86 & 89 & 52 & 8 & 2 & 16 & 14 \\
\hline & $\begin{array}{l}\text { All } \\
\text { Farmers }\end{array}$ & 190 & 25 & 9 & 216 & 80 & 59 & 43 & 8 & 3 & 45 & 52 \\
\hline & Sig. & & \multicolumn{2}{|c|}{0.000} & \multicolumn{2}{|c|}{0.000} & \multicolumn{2}{|c|}{0.000} & \multicolumn{2}{|c|}{0.928} & \multicolumn{2}{|c|}{0.000} \\
\hline 2003 & FFS Plot* & 26 & 18 & 10 & 85 & 47 & 13 & 10 & 6 & 4 & 145 & 49 \\
\hline
\end{tabular}

*FFS plot refers to a field used by farmers during season long training to take field observations, analyse data and make crop production decisions.

this practice is questionable. Most importantly, FFS farmers significantly increased the time spent on field observation as compared to the other two groups. This illustrates that one of the main messages of the training, i.e. to regularly observe the cotton fields was well taken up by the participants.

The pre- and post-training fertiliser management observed no change and the differences among various groups remained significant whereas the irrigation management results got reversed, i.e. there was a significant difference before the training but there was none in 2003. This could be attributed to change in microclimatic factors and is not necessarily associated with the training. Application of irrigation was almost identical in terms of absolute numbers, but varied in relation to timing and volume of application.

The paired comparisons make the changes after the training more transparent (Table 4). For example, it shows that Non-FFS farmers had also increased the time spent on field observations hinting some diffusion effect. Comparing these differences for FFS and control farms shows that use of material inputs at FFS farms declined relative to the control group. Also, the differences were generally large like those between Non-FFS and Control. The most pronounced change as indicated above was in the time spent on field observations. 
Table 4

Paired Difference in Production Practices by Farmer Groups

\begin{tabular}{|c|c|c|c|c|c|c|c|c|c|}
\hline & \multicolumn{3}{|c|}{ Pre/post FFS Diff. } & \multicolumn{3}{|c|}{ FFS-Control } & \multicolumn{3}{|c|}{ Non-FFS-Control } \\
\hline & FFS & $\begin{array}{l}\text { Non- } \\
\text { FFS }\end{array}$ & $\overline{\text { Control }}$ & Pre & Post & $\overline{\text { Diff. }}$ & Pre & Post & Diff. \\
\hline Seed Rate (kg/ha) & $\begin{array}{c}2 \\
(6.5)\end{array}$ & $\begin{array}{c}2 \\
(7.9)\end{array}$ & $\begin{array}{c}8 \\
(9.1)\end{array}$ & -2 & -8 & -6 & -2 & -8 & -6 \\
\hline N (kg/ha) & $\begin{array}{l}16 \\
(81)\end{array}$ & $\begin{array}{c}13 \\
(65)\end{array}$ & $\begin{array}{c}51 \\
(91)\end{array}$ & -47 & -82 & -35 & -57 & -95 & -38 \\
\hline P (kg/ha) & $\begin{array}{l}-7 \\
(31)\end{array}$ & $\begin{array}{l}-5 \\
(37)\end{array}$ & $\begin{array}{c}22 \\
(54)\end{array}$ & -15 & -44 & -29 & -13 & -40 & -27 \\
\hline $\begin{array}{l}\text { Field Observations } \\
\text { (hrs/ha) }\end{array}$ & $\begin{array}{c}30 \\
(85)\end{array}$ & $\begin{array}{c}12 \\
(65)\end{array}$ & $\begin{array}{c}-1 \\
(21)\end{array}$ & 19 & 50 & 31 & 15 & 28 & 13 \\
\hline
\end{tabular}

\section{Difference in Pesticide Use}

Pesticide use is a variable of major concern in the assessment of FFS training. Therefore, detailed account of pesticide use practices was taken for before and after training scenario. The total number of pesticide applications differed significantly among three groups in pre- as well as post FFS training period (Table 5). The control farmers had the highest pesticide application frequency in both the periods. In terms of pesticide quantity applied, FFS farmers had the highest input among the three groups of farmers in pre-FFS training period (in 2001). However, looking at the distribution of application over various stages of crop growth no clear pattern of difference was observed during the same year.

Table 5

Pesticide Use in Terms of Number and Doses at Different Crop Growth Stages

\begin{tabular}{|c|c|c|c|c|c|c|c|c|c|c|c|c|}
\hline \multirow[b]{2}{*}{ Year } & \multirow[b]{2}{*}{ Types } & \multirow[b]{2}{*}{$\mathrm{N}$} & \multicolumn{2}{|c|}{$\begin{array}{l}\text { Pesticide } \\
\text { Applications } \\
\text { (No/Season) }\end{array}$} & \multicolumn{2}{|c|}{$\begin{array}{c}\text { Total } \\
\text { Pesticide Doses } \\
(\mathrm{ml} / \mathrm{ha})\end{array}$} & \multicolumn{2}{|c|}{$\begin{array}{l}\text { Vegetative Stage } \\
\text { Applications } \\
\text { (No/Season) }\end{array}$} & \multicolumn{2}{|c|}{$\begin{array}{l}\text { Flowering Stage } \\
\text { Applications } \\
\text { (No/Season) }\end{array}$} & \multicolumn{2}{|c|}{$\begin{array}{c}\text { Boll } \\
\text { Stage } \\
\text { Applications } \\
\text { (No/Season) }\end{array}$} \\
\hline & & & Mean & SD & Mean & $\overline{S D}$ & Mean & SD & Mean & SD & Mean & SD \\
\hline \multirow[t]{5}{*}{2001} & FFS & 78 & 4.13 & 1.34 & 7979.32 & 2944 & 1.17 & 0.61 & 1.08 & 0.58 & 1.88 & 1.13 \\
\hline & Non-FFS & 59 & 3.71 & 1.68 & 7230.56 & 2768 & 1.10 & 0.64 & 0.97 & 0.56 & 1.58 & 1.16 \\
\hline & Control & 53 & 5.15 & 1.26 & 6986.00 & 1877 & 1.89 & 0.85 & 1.13 & 0.59 & 2.08 & 1.27 \\
\hline & Overall & 190 & 4.41 & 1.51 & 7709.00 & 2683 & 1.35 & 0.77 & 1.06 & 0.57 & 1.84 & 1.19 \\
\hline & Sig. & & \multicolumn{2}{|c|}{0.000} & \multicolumn{2}{|c|}{0.010} & \multicolumn{2}{|c|}{0.000} & \multicolumn{2}{|c|}{0.291} & \multicolumn{2}{|c|}{0.078} \\
\hline \multirow[t]{5}{*}{2003} & FFS & 78 & 3.53 & 1.93 & 4484.33 & 3095 & 0.17 & 0.44 & 0.73 & 0.75 & 2.62 & 1.68 \\
\hline & Non-FFS & 59 & 4.00 & 2.07 & 5706.37 & 4557 & 0.25 & 0.60 & 0.69 & 0.79 & 3.05 & 1.63 \\
\hline & Control & 53 & 6.21 & 1.78 & 9299.00 & 3658 & 0.64 & 0.76 & 1.26 & 0.68 & 4.30 & 1.61 \\
\hline & Overall & 190 & 4.58 & 2.18 & 6518.00 & 4150 & 0.33 & 0.62 & 0.87 & 0.78 & 3.22 & 1.78 \\
\hline & Sig. & & \multicolumn{2}{|c|}{0.000} & \multicolumn{2}{|c|}{0.000} & \multicolumn{2}{|c|}{0.000} & \multicolumn{2}{|c|}{0.000} & \multicolumn{2}{|c|}{0.000} \\
\hline
\end{tabular}


The year 2003 was highly wet and had pest outbreaks at the boll formation stage as a result pesticide use had increased on all types of sample farms during this stage. While the FFS farmers also applied more number of sprays during this year, however, the increase was smaller than that in case of other groups of farmers. This indicates that FFS farmers have gained confidence from conducting their field observations and behaved accordingly.

The pesticide use at FFS farms declined in terms of frequency as well as dosage whereas only the pesticide dosage was reduced at Non-FFS farmers (Table 6). The differences were more pronounced when comparing FFS and control versus Non-FFS and control farmers. These differences in the number and dosage of pesticide application can be considered to be the result of the trained farmers' better understanding of the pest situation in the field.

Table 6

Paired Difference Comparisons for Pesticide Usage

\begin{tabular}{|c|c|c|c|c|c|c|c|c|c|}
\hline & \multicolumn{3}{|c|}{ Pre/Post FFS Diff. } & \multicolumn{3}{|c|}{ FFS-Control } & \multicolumn{3}{|c|}{ Non-FFS-Control } \\
\hline & FFS & $\begin{array}{l}\text { Non- } \\
\text { FFS }\end{array}$ & Control & Pre & Post & Diff. & Pre & Post & Diff. \\
\hline Insecticide (No/Season) & $\begin{array}{c}-0.57 \\
(1.9)\end{array}$ & $\begin{array}{l}0.37 \\
(1.7)\end{array}$ & $\begin{array}{l}1.06 \\
(2.0)\end{array}$ & -1.02 & -2.68 & -1.66 & -1.44 & -2.21 & -0.77 \\
\hline Insecticide Dose (Litre/Ha) & -3.5 & -1.5 & 2.3 & 1 & -4.8 & -5.8 & 0.2 & -3.6 & -3.8 \\
\hline
\end{tabular}

Note: Figures in parenthesis are Standard Deviations.

\section{Gross Margin Differences}

The comparison of the economic performance of the three groups of farmers before and after the training is depicted in Table 7. There existed no significant difference in yield and gross margin among various farm categories before the training (i.e. during year 2001). However, for pesticide and fertiliser costs significant differences existed among farm groups, with highest costs of these inputs at the control farms during the same year. The same comparison showed that the differences among group were significant for all variables during 2003. The cotton yields were lower in 2003 on all farm categories because of high pest infestation and excessive vegetative growth. It can be observed that the yields differed significantly among various farm groups in this year and the FFS farms obtained relatively higher cotton yields than those realised by the other farm categories. 
Table 7

Cotton Yields, Revenue, Gross Margin and Cost Comparisons

\begin{tabular}{|c|c|c|c|c|c|c|c|c|c|c|c|c|}
\hline \multirow[b]{2}{*}{ Year } & \multirow[b]{2}{*}{ Types } & \multirow[b]{2}{*}{$\mathrm{N}$} & \multicolumn{2}{|c|}{$\begin{array}{c}\text { Yield } \\
(\mathrm{kg} / \mathrm{ha})\end{array}$} & \multicolumn{2}{|c|}{ Revenue (US\$/ha) } & \multicolumn{2}{|c|}{$\begin{array}{c}\text { Gross Margin } \\
\text { (US\$/ha) }\end{array}$} & \multicolumn{2}{|c|}{$\begin{array}{c}\text { Pesticide Cost } \\
\text { (US\$/ha) }\end{array}$} & \multicolumn{2}{|c|}{$\begin{array}{c}\text { Fertiliser Cos } \\
\text { (US\$/ha) }\end{array}$} \\
\hline & & & Mean & $\mathrm{SD}$ & Mean & $\overline{\mathrm{SD}}$ & Mean & $\mathrm{SD}$ & Mean & $\mathrm{SD}$ & Mean & SD \\
\hline \multirow[t]{5}{*}{2001} & FFS & 78 & 2137 & 697 & 708 & 237 & 140 & 218 & 74 & 31 & 94 & 38 \\
\hline & Non-FFS & 59 & 1985 & 754 & 671 & 260 & 125 & 244 & 72 & 37 & 95 & 34 \\
\hline & Control & 53 & 2111 & 687 & 694 & 240 & 50 & 286 & 144 & 207 & 121 & 39 \\
\hline & Overall & 190 & 2083 & 712 & 693 & 245 & 111 & 248 & 93 & 117 & 102 & 39 \\
\hline & Sig. & & \multicolumn{2}{|c|}{0.444} & \multicolumn{2}{|c|}{0.686} & \multicolumn{2}{|c|}{0.107} & \multicolumn{2}{|c|}{0.000} & \multicolumn{2}{|c|}{0.000} \\
\hline \multirow[t]{5}{*}{2003} & FFS & 78 & 1487 & 393 & 925 & 248 & 391 & 267 & 48 & 37 & 105 & 38 \\
\hline & Non-FFS & 59 & 1079 & 373 & 660 & 223 & 151 & 250 & 61 & 48 & 100 & 46 \\
\hline & Control & 53 & 1242 & 552 & 688 & 335 & 25 & 320 & 123 & 66 & 160 & 59 \\
\hline & Overall & 190 & 1292 & 469 & 777 & 294 & 215 & 317 & 73 & 59 & 119 & 54 \\
\hline & Sig. & & \multicolumn{2}{|c|}{0.000} & \multicolumn{2}{|c|}{0.000} & \multicolumn{2}{|c|}{0.000} & \multicolumn{2}{|c|}{0.000} & \multicolumn{2}{|c|}{0.000} \\
\hline 2003 & FFS Plot & 26 & 1482 & 563 & 941 & 369 & 513 & 322 & 000 & 000 & 38 & 28 \\
\hline
\end{tabular}

The differences for yields and gross margins are portrayed more clearly in Table 8. Even though yields declined for all three groups, yet the gross margin of FFS farmers did increase as they experienced relatively lower reduction in cotton yield while at the same time reduced the use of pesticides and fertiliser inputs. The results further reveal that the positive gross margin difference was more pronounced at FFS farms of smaller size. Similar to the previous performance parameters the difference between FFS farmers and control farmers was higher and more uniform than those between Non-FFS and control. While difference of difference in yield was negative for non-FFS versus control, the difference in gross margin was less than one fifth of the difference between FFS versus control.

Table 8

Differences of Difference Estimates for Crop Production and Income

\begin{tabular}{|c|c|c|c|c|c|c|c|c|c|}
\hline & \multicolumn{3}{|c|}{ Pre/Post FFS Diff. } & \multicolumn{3}{|c|}{ FFS-Control } & \multicolumn{3}{|c|}{ Non-FFS-Control } \\
\hline & FFS & $\begin{array}{c}\text { Non- } \\
\text { FFS }\end{array}$ & Control & $\overline{\text { Pre }}$ & Post & Diff. & Pre & Post & Diff. \\
\hline GM (\$/ha) & $\begin{array}{c}251 \\
(338)\end{array}$ & $\begin{array}{c}26 \\
(337)\end{array}$ & $\begin{array}{c}-25 \\
(380)\end{array}$ & 90 & 366 & 276 & 75 & 126 & 51.16 \\
\hline Yield (kg/ha) & $\begin{array}{l}-650 \\
(771)\end{array}$ & $\begin{array}{l}-906 \\
(837)\end{array}$ & $\begin{array}{l}-869 \\
(735)\end{array}$ & 26 & 245 & 219 & -126 & -163 & -37.05 \\
\hline GM-(<2 ha Farmers $)$ & $\begin{array}{l}322.0 \\
(355)\end{array}$ & $\begin{array}{c}0.1 \\
(339)\end{array}$ & $\begin{array}{c}62.0 \\
(344)\end{array}$ & 0 & 414 & 414 & 66 & 158 & 92 \\
\hline GM (>4 ha Farmers) & $\begin{array}{c}211 \\
(418) \\
\end{array}$ & $\begin{array}{c}133 \\
(209) \\
\end{array}$ & $\begin{array}{c}-6 \\
(441) \\
\end{array}$ & 158 & 376 & 218 & -55 & 85 & 140 \\
\hline
\end{tabular}

Note: Figures in parenthesis are Standard Deviations. 


\section{Stochastic Production Frontier Analysis}

The stochastic production frontier model incorporating inefficiency effects specified in Equations 1 and 2 were estimated using the computer programme "FRONTIER 4.1" written by Tim Coelli of the University of New England, Armidale, Australia. The programme follows a three step procedure for model estimation and permits the use of panel data like the data set being used for the current study. The results of the estimated models (Equations 1 and 2) are presented in Tables 9 and 10.

Table 9

OLS and Maximum Likelihood Estimates of the Cobb-Douglas Stochastic Frontier Model

\begin{tabular}{|c|c|c|c|c|c|}
\hline \multirow[b]{2}{*}{ Variable } & \multirow[b]{2}{*}{ Parameter } & \multicolumn{2}{|c|}{ OLS } & \multicolumn{2}{|c|}{ MLE } \\
\hline & & Estimate $\beta$ & $t$-statistic & Estimates & $t$-statistics \\
\hline Constant & $\beta_{0}$ & 3.5018* & 10.9024 & $3.0615^{*}$ & 15.7055 \\
\hline $\operatorname{Ln}(L A B O U R)$ & $\beta_{1}$ & $0.9982 *$ & 27.1809 & $1.0166^{*}$ & 41.6478 \\
\hline $\operatorname{Ln}(S E E D)$ & $\beta_{2}$ & $0.1038 * *$ & 2.4583 & $0.1025 *$ & 3.9832 \\
\hline DCHEM & $\beta_{3}$ & 0.1284 & 0.5515 & -0.2309 & -1.4387 \\
\hline $\operatorname{Ln}(\mathrm{CHEM})$ & $\beta_{4}$ & 0.0239 & 0.9756 & -0.0174 & -1.0051 \\
\hline $\operatorname{Ln}(N F E R T)$ & $\beta_{5}$ & $-0.0989 * *$ & -2.4896 & 0.0037 & 0.1865 \\
\hline DPFERT & $\beta_{6}$ & $-0.5152 *$ & -3.0559 & -0.0702 & -0.7174 \\
\hline $\operatorname{Ln}(P F E R T)$ & $\beta_{7}$ & $-0.1181^{*}$ & -2.9586 & -0.0167 & -0.6953 \\
\hline \multicolumn{2}{|c|}{ Log Likelihood Function } & -2.3969 & & 80.5119 & \\
\hline
\end{tabular}

*, **, *** Significant at 1,5 , and 10 percent level respectively.

Table 10

Estimates of Inefficiency Model

\begin{tabular}{lccc}
\hline Variable & Parameter & Estimate $\delta$ & $t$-statistics \\
\hline Constant & $\delta_{0}$ & 0.2448 & 1.2326 \\
DYEAR & $\delta_{1}$ & $-1.6304^{*}$ & -2.6932 \\
DMFFS & $\delta_{2}$ & $-0.2207^{* *}$ & -1.9323 \\
AGE & $\delta_{3}$ & -0.0023 & -0.6255 \\
DPRIMARY & $\delta_{4}$ & 0.0446 & 0.5049 \\
DMATRIC & $\delta_{5}$ & -0.0853 & -0.7868 \\
DHIGHER & $\delta_{6}$ & -0.2087 & -1.5086 \\
Sigma Squared & $\sigma^{2}$ & $0.1918^{*}$ & 3.1974 \\
Gamma & $\gamma$ & $0.9746^{*}$ & 100.2054 \\
Log Likelihood Function & 130.7811 & & \\
LR Test & 266.3560 & & \\
******* Significant at 1, 5, and 10 percent level respectively. &
\end{tabular}


The presence of inefficiency effects was tested by assuming the following null hypothesis.

$$
H_{0}: \gamma=\delta_{0}=\delta_{1}=\delta_{2}=\delta_{3}=\delta_{4}=\delta_{5}=\delta_{6}=0
$$

This hypothesis implies that the variance of inefficiency term, $u_{i}$, [i.e. $\sigma_{u}^{2}$ ] is equal to zero indicating that technical inefficiency effects are not part of the model. These restrictions further show that the stochastic frontier function given in Equations 1 and 2 is equivalent to a traditional average production function and thus can be estimated using OLS procedure.

The likelihood ratio test rejected the null hypothesis. ${ }^{2}$ The second hypothesis relates to whether the explanatory variables given in inefficiency model affect the farm-level inefficiency or not. The relevant null hypothesis is written as

$$
H_{0}: \delta_{1}=\delta_{2}=\delta_{3}=\delta_{4}=\delta_{5}=\delta_{6}=0 \text {. }
$$

It implies that the explanatory variables given in the technical inefficiency model have zero coefficients. This hypothesis was also rejected at 1 percent level of significance. Therefore, it can be concluded that the variables included in the inefficiency model significantly explain variation in farm level technical inefficiencies.

The statistical tests have shown that stochastic frontier model incorporating inefficiency component is the preferred specification. The parameter estimate of $\gamma$ is found to be 0.975 , which is closer to 1.0. This coefficient also indicates that technical inefficiency effects are significant in the stochastic frontier model [Battese, Malik and Gill (1996)]. The results show that labour input and seed rate have positive effect on cotton yield as both the variables have positive elasticities that are statistically significant at 1 and 10 percent level respectively. The farmers of the area use an average seed rate considered to be high. They could not obtain optimal plant population due to use of banned varieties, low quality seed, soil salinity, and faulty sowing methods.

The results reveal that application of chemicals has an insignificant effect on yield hinting that higher use of chemicals not necessarily result in higher yields. Similarly, the fertiliser nutrients (nitrogen as well as phosphorus) have insignificant effect on cotton yield. The small and insignificant elasticity coefficients for these variables suggest that use of fertiliser and chemicals can be reduced without any significant reduction in cotton yield. So some potential gains can be realised through environmental improvement on account of reduced fertiliser and chemical use.

${ }^{2}$ The likelihood-ratio (LR) test can be written as: $\mathrm{LR}=2\left[\mathrm{LL}\left(\mathrm{H}_{1}\right)-\mathrm{LL}\left(\mathrm{H}_{0}\right)\right]$. Where, $\operatorname{LL}\left(\mathrm{H}_{0}\right)$ and $\mathrm{LL}\left(\mathrm{H}_{1}\right)$ are the log likelihood functions under the null and alternate hypotheses, respectively. The LR statistic has an asymptotic Chi-square distribution with degrees of freedom equal to the difference between the number of parameter estimates in the unrestricted and restricted models. The value of computed LR was 266, which is higher than critical $\chi^{2}$ value (20.09). 
The results for technical inefficiency component reveal that the farm level technical efficiencies ranged from about 18 percent (at the most inefficient farm) to 98 percent (at the most efficient farm) with the mean technical efficiency of 81 percent during the study period. Thus the average cost of inefficiencies amounted to 19 percent. The technical efficiencies were generally higher during 2001(a normal year) as compared to those in 2003 which was a bad year for cotton production (Figure 1). The dummy variable DMFFS has a negative and statistically significant coefficient at 5 percent level. It implies that skill development among farmers through FFS trainings helped in improving farm level technical efficiency. Coupled with the insignificant parameters of educational dummy variables DPRIMARY, DMATRIC, and DHIGHER in the same model suggest that the technical education is more important than general education in order to enhance farm level efficiency. Ahmad, et al. (2002) found formal education as well as extension contact (for technical guidance) as significant factors in determining farm level technical efficiency in case of wheat production. The insignificant role of general education found in our study may be due to the fact that cotton production is relatively a more technical enterprise than wheat production.

Fig. 1. Farm Level Technical Efficiency (All Farms)

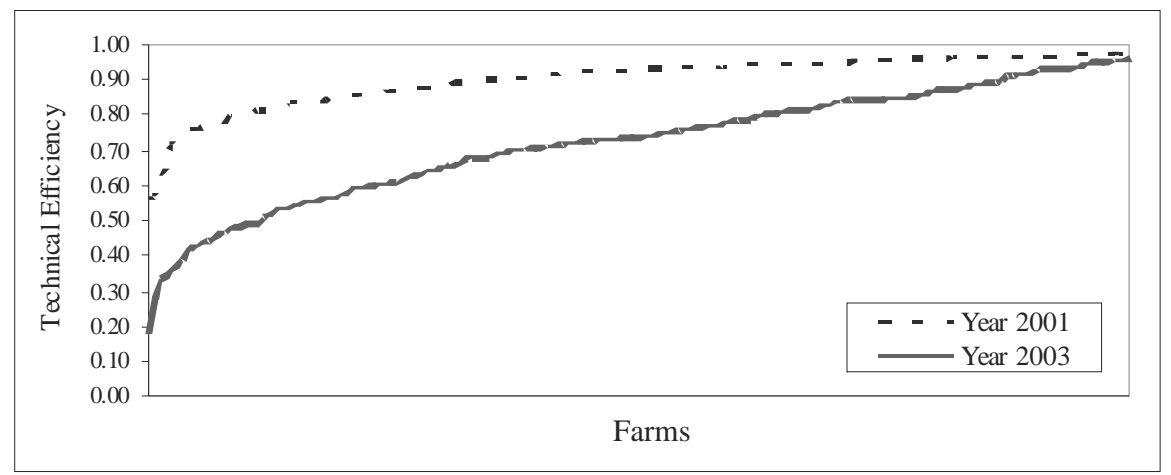

The coefficient of AGE variable in inefficiency model is positive but insignificant implying that technical inefficiency is not associated with farmers' age. In general the older people are less educated, more risk averse and reluctant to experiment with new technologies. The farm level technical efficiencies at FFS and non FFS farms were comparable during the year 2001 showing that the sample farmers were almost at the same level of efficiency in pre FFS period (Figure 2). Though the technical efficiencies were generally low during 2003 (a bad cotton year) but the FFS farms depicted a higher level of efficiency than their counterparts (Figure 3). The cost of inefficiency at FFS farms was lower (23.71 percent) as 
Fig. 2. Technical Efficiency at FFS and Non-FFS Farms (2001)

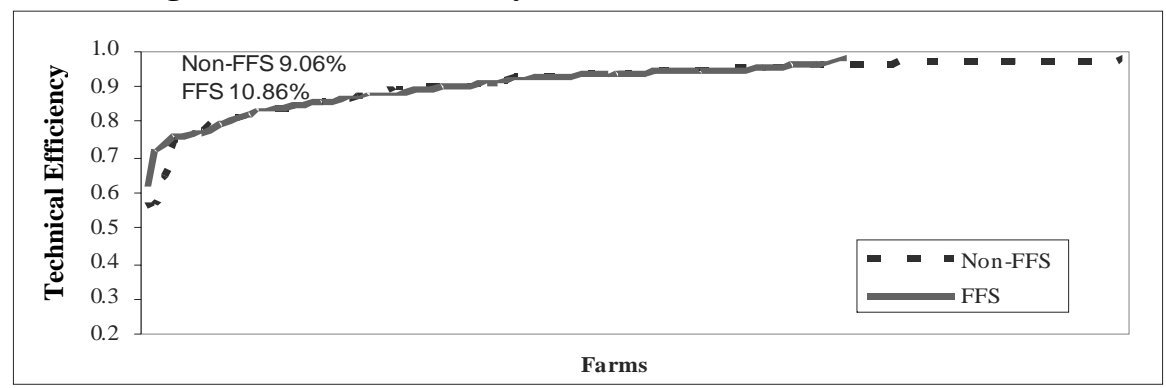

Fig. 3. Efficiency at FFS and Non-FFS Farms (2003)

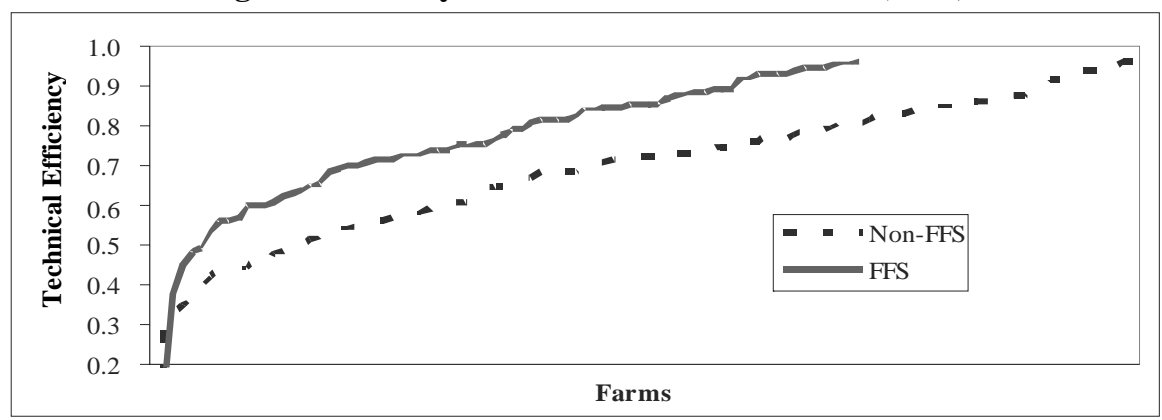

compared to that on non-FFS farms (30.50 percent) as shown by the non shaded area in Figure 4 and 5 respectively. It implies that FFS farmers were able to maintain higher level of efficiency even under abnormal climatic conditions. A higher average technical efficiency obtained at FFS farms (higher by about 7 percent) than that achieved on Non-FFS farms may clear the doubt in the mind of policy-makers that FFS approach may only be cost efficient but not technically efficient.

Fig. 4. Efficiency at FFS Farms (2003)

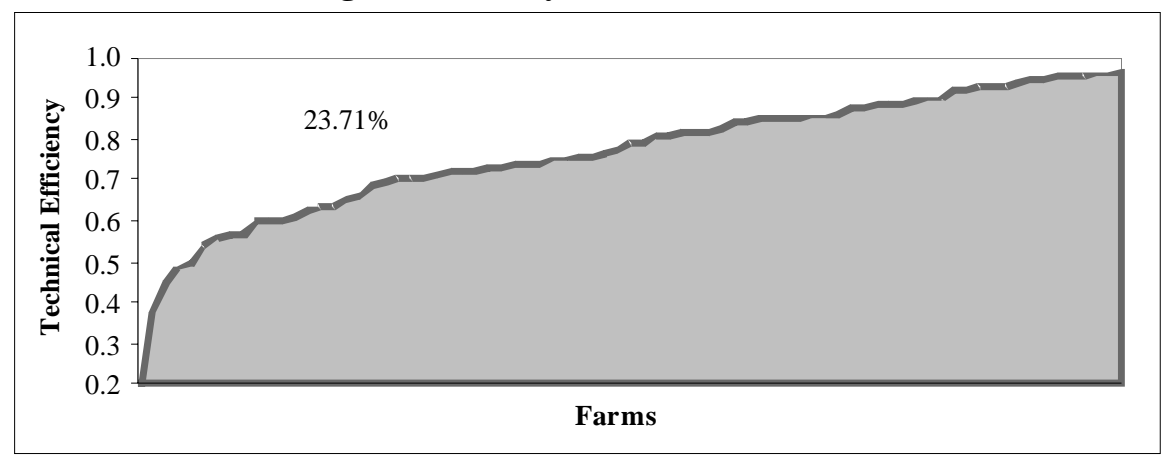


Fig. 5. Efficiency at Non-FFS Farms (2003)

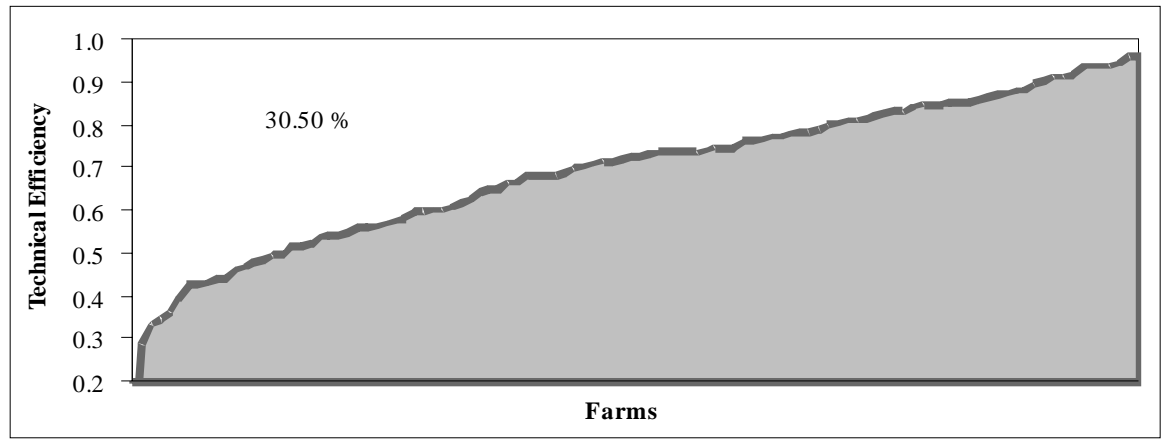

\section{CONCLUSIONS AND RECOMMENDATIONS}

FFS-type farmer education implemented in Pakistan has provided farming communities with opportunities to learn improved cotton management in a participatory way. As a result of the season-long training, farmers' skills for making rational and informed decisions were significantly enhanced. The field observation, situation analysis, and decision-making capacities have improved to a greater extent among FFS farmers. This has contributed to more cost effective and environmental friendly crop management decisions. The high input costs at control farms show that the management of major inputs like seeds, fertiliser, and irrigation scheduling were noticeably neglected at these farms whereas these issues have received due attention by the FFS farmers. It is thus plausible that the difference in gross margins has increased among FFS farms and non-FFS and especially between FFS and control farms.

The results indicate that farmers' dependence on the use of highly toxic chemicals can be reduced through training and the adoption of various cultural and biological methods. The results show that technical efficiency at FFS graduate farms has enhanced as a result of skill development among them. The results further confirm that FFS approach has the potential of achieving higher production efficiency along with additional environmental and health gains. However, further analysis and data collection is warranted to confirm these indicative results in the long run. Planning, record keeping, situation analysis, and interpretation aspects of these experiments by farmers need further backup support to strengthen this crucial component of sustaining IPM practices.

In order to enable farming communities to draw valid conclusions from their own experimentation as initiated by FFS, a well-planned technical backup support mechanism should be established. In this context, the integration of the research system and farming communities in Pakistan is the pre-requisite to establish a sound foundation for such collaborative experimentation. At the outset, the researchable 
issues should be well conceived during FFS training sessions through asking critical questions on major differentials in the data generated during agro-ecosystem analyses (AESA) by the farmers.

In order to assure that the farmers will sustain FFS activities, farming communities should be given the right kind of incentives to continue working as a group. Institutionalised collective action is vital if cotton pest management in Pakistan is to become safer, more efficient and more environment friendly. Finally, a strategy for transforming the extension service in Pakistan towards a more participatory and self-reliant system should be persuaded.

\section{REFERENCES}

Abbot, J., and I. Guijt (1998) Changing Views on Change: Participatory Approaches to Monitoring the Environment. International Institute for Environment and Development London. (SARL Discussion Paper No. 2.)

Ahad, K., Y. Hayat, and I. Ahmad (2001) Capillary Chromatographic Determination of Pesticide Residues in Multan Division. The Nucleus 38:2, 145-149.

Ahmad, I., and A. Poswal (2000) Cotton Integrated Pest Management in Pakistan: Current Status. Country Report presented in Cotton IPM Planning and Curriculum Workshop organised by FAO, Bangkok, Thailand. February 28March 2.

Ahmad, Munir, G. Mustafa Chaudhry, and M. Iqbal (2002) Wheat Productivity, Efficiency, and Sustainability: A Stochastic Production Frontier Analysis. The Pakistan Development Review 41:4, 643-663.

Azeem, M. K., M. Iqbal, M. H. Soomro, and Iftikhar Ahmad (2003) Economic Evaluation of Pesticide Use Externalities in the Cotton Zone of Punjab, Pakistan. The Pakistan Development Review 41:4, 683-698.

Azeem, M. (2000) Economics Evaluation of Pesticide Externalities in Cotton Zones of Punjab Pakistan. Report for the UNDP Study, FAO, Rome, Italy.

Battese, G. E., S. J. Malik, and M. A. Gill (1996) An Investigation of Technical Efficiencies of Production of Wheat Farmers in Four Districts of Pakistan. Journal of Agricultural Economics 47, 37-49.

Battese, G. E., and T. J. Coelli (1995) A Model for Technical Inefficiency Effects in Stochastic Frontier Function for Panel Data. Empirical Economics 20, 325-332.

Berg H.v d., Oooi P. A. C., A. L. Hakim, H. Ariawan, and W. Cahyana (2004) Farmer Field Research: An Analysis of Experices in Indonesia, FAO-EU Programme for Cotton in Asia, Regional Office of Asia and the Pacific Bangkok.

Casley, D. J., K. Kumar (1987) Project Monitoring and Evaluation in Agriculture. Baltimore: The John Hopkins University Press, London.

Feder, G., R. Murgai, and J. B. Quizon (2003) Sending Farmers Back to School: The Impact of Farmer Field Schools in Indonesia. Review of Agricultural Economics 26:1, 1-18. 
Feenstra, S., A. Jabbar, R. Masih, and W. A. Jehangir (2000) Health Hazards of Pesticides in Pakistan. Islamabad: IWMI and PARC.

Guijt, I. (1998) Participatory Monitoring and Impact Assessment of Sustainable Agriculture Initiatives-An introduction to the Key Elements. International Institute for Environment and Development, London. (SARL Discussion Paper No. 1.)

Irshad, M. (2000) Status of Pesticide Resistance in Pakistan. Consultancy Report Submitted to FAO under Project No. PAK/99/002, FAO Pakistan, Islamabad.

Orphal, J. (2001) Economics of Pesticide Use in Cotton Production in Pakistan, Diploma Thesis, University of Hannover, Germany.

Praneetvatakul, S., and H. Waibel (2001) A Socio-economic Analysis of Farmer's Drop-out from Training Programmes in Integrated Pest Management. Paper presented at the workshop on "Participatory Technology Development and Local Knowledge for Sustainable Land Use in Southeast Asia”, 6-7 June. Chiang Mai, Thailand.

Poswal, M. A., and S. Williamson (1998) Stepping off the Cotton Pesticide Treadmill: Preliminary Findings from a Farmer's Participatory Cotton IPM Training Project in Pakistan. CABI Bioscience Centre, Rawalpindi.

UNDP (2001) Policy and Strategy for the Rational Use of Pesticides in Pakistan, Building Consensus for Action, UNDP/FAO Paper Rome, Italy. 


\section{Comments}

My comments are as follows:

(a) general comments;

(b) specific comments pertaining to the objectives, methods, data collection and transformations, analytical methods, results and discussions, conclusion and suggestions; and

(c) miscellaneous.

\section{General Comments}

(i) The topic of the paper is very much relevant to the theme of the 21st Annual Conference of Pakistan Society of Development Economists; and it also falls in my interest and expertise areas of socio-economic and cultural studies.

(ii) Overall, the paper is written professionally by giving due weight age to each desired components of a scientific/research documentation including justification, scope and objectives, methods, results and discussion and conclusions and recommendations.

(iii) With the permission of the chair, let me allow to pay my duties by commenting critically on the strengths and short comings of the paper in details, please.

\section{Specific Comments}

\section{(i) Objectives}

Out of the four objectives of this paper, the 2nd objective, "to assess farmers' ability to retain knowledge and practice skills learned through farmers field school (FFS)", has not adequately addressed in the scope of the paper by the speakers. It is a part of cognitive skill development because, it also warrants the validity and reliability of the study results through a Delphi panel, and number of other means. For example, some of the judging attributes may cover these, including (a) consistency; (b) accuracy; and (c) clarity of the messages to be retained in short as well as long term memory by the participating members of the FFS. It was not discussed in the paper, thus there is a need to either drop this objective or reword to qualify appropriately. 


\section{(ii) Methods}

The justification of the sample size versus the reported number of observations is not given and unclear for the readers. Wherein, out of 220 samples size only 190 observation were reported and interpreted but dropping of 30 observations is not clearly spelled out which need to be justified accordingly. A detail description was not given concerning to the selection of sample control village in Sukkur district which seems to be significantly different in terms of productivity profile as well as other socio-economic traits from the selected FFS village in Khairpur district. This difference shall make discrepancy while performing the performance analysis of the key interventions between FFS selected village and control village.

\section{(iii) Data Collection and Transformations}

The reference used for developing scoring on "field experimentation skills assessment" is not clear in terms of weights allotted to different traits/stimuli. If we assume, it is justified then elaborate the philosophy with quoting reference, behind the weights given to different traits. Also check the accumulation of the scoring that may arrive at 100, but it counted to be 110 towards "decision-making empowerment scoring” trait.

\section{(iv) Analytical Methods}

The suitability of the models is my major concern here, especially when we are dealing with exogenous causal factors rather than factors of production like, pesticide use-unlike, seed, fertiliser and irrigations (factors of production). Moreover, the pesticide use is not productivity enhancing factor but a protection measure. Under this situation, whether the authors think that Stochastic Production Frontier model is still the best and more relevant one rather choosing some recursive models by simulating when needed under the prevailing situation of the pest attack, and in turn that make any economically significant loss towards the productivity of cotton or other wise. As I understand, although the authors of this paper tried their best to tackle this issue partly by incorporating the technical inefficiency component for the analysis of the available data. A caution is needed to highlight while interpreting the results of this sort of studies.

Some of the major shortcomings have seen in the choice of the most relevant and important explanatory variables and their nature under Stochastic Production Frontier model by the analysts. For example, seed rate was picked without taking into account the improved vs. traditional variety use as well as the weeding operation (either manual or chemical) as an explanatory variable is not included in the production function. With the inclusion of the aforementioned independent variables, 
the precision in the contribution of the already included factors may have increased towards the real rather than over laden with co-linearity and interaction effects.

The discussion of limitations of the analytical tools employed in this paper may also be given in the paper for the usefulness of the readers/future researchers.

\section{(v) Results and Discussion}

The power of useful information generated by employing the simple analyses including gap/discrepancy, descriptive statistics, gross margin and cost comparisons is evident from the interpretation of the study results, presented in Tables 1 through 8.

The study results proved the significance of FFS' informal technical training towards achieving sustainable cotton production as per information generated by using the simple analytical techniques but lot more to know through arresting the similar contributions of FFS' efforts by employing the sophisticated models on the pattern of this paper analyses. As learned from the results of this study that general education does not contribute significantly towards the sustainable cotton production that also supported to popularise the vocational crop related education on the pattern of FFS.

Some of the interpretations out of this model need to be revisited and warranted more clear explanations, for example labour and seed rates inputs have positive effects on crop yield. In the light of above discussion, the signs of both of the parameters are in right direction, but many of the key and independent operations are hidden with these factors of production including higher seed rate application is not only restricted to maintain the desired plant population of cotton crop but a dummy to suppress the weeds. At the same time labour is being used to manifest the operations of thinning of the crop to arrive at desired plant population as well as weed out the noxious plants. An allowance to skilled and non-skilled labour is not clearly spelled out for other than pesticide inputs being used for sustaining the cotton production. Moreover, a comprehensive analysis with careful choice of parameters is recommended to clearly segregate the contributions of all these important factors in order to give adequate share to interactions effects as well as free from inbuilt limitations of the models.

\section{(vi) Conclusion and Suggestions}

The authors acknowledged by themselves through cautioning the word "indicative results" that reiterated a care is needed while interpreting the implications of this study results.

FFS approach can't be institutionalised until and unless its cost effectiveness shall be established vis-à-vis the prevailing approaches of Agricultural extension under the present and suggested structure/restructure roles of the respective stakeholders, especially public and civil societies/private sector. 


\section{Miscellaneous}

- "FFS plot" terminology is used in some of the tables in the paper that is not clear to the readers. Thus it needs to be elaborated.

- Figures 4 and 5 need clear interpretation that is presently confusing. Some more clarification is needed for understanding.

- A few references quoted but not cited properly that needs to be corrected.

Pakistan Agricultural Research Council,

Ikram Saeed

Islamabad. 